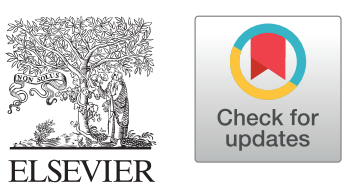

\title{
Review
}

\section{Years After the First Woman Cardiac Surgeon: We Still Need More Women in Cardiac Surgery}

\author{
Sophie Weiwei Gao, MD, ${ }^{a}$ Jessica Forcillo, MD, MSc, ${ }^{b}$ Amelia Claire Watkins, MD, ${ }^{c}$ \\ Mara B. Antonoff, MD, ${ }^{d}$ Jessica G.Y. Luc, MD, ${ }^{e}$ Jennifer C.Y. Chung, MD, MSc, ${ }^{f}$ \\ Laura Ritchie, MD, ${ }^{a}$ Rachel Eikelboom, MD, ${ }^{\mathrm{g}}$ Subhadra Shashidharan, MD, ${ }^{\mathrm{h}}$ \\ Michiko Maruyama, MD, ${ }^{i}$ Richard P. Whitlock, MD, PhD, ${ }^{a}$ Maral Ouzounian, MD, PhD, ${ }^{f}$ and \\ Emilie P. Belley-Côté, MD, $\mathrm{PhD}^{j}$ \\ ${ }^{a}$ Department of Surgery, Division of Cardiac Surgery, McMaster University, Hamilton, Ontario, Canada \\ ${ }^{b}$ Department of Cardiac Surgery, Division of Cardiac Surgery, Université de Montréal, Montreal, Quebec, Canada \\ ${ }^{c}$ Department of Cardiothoracic Surgery, Stanford University, Stanford, California, USA \\ ${ }^{d}$ Department of Thoracic and Cardiovascular Surgery, University of Texas MD Anderson Cancer Center, Houston, Texas, USA \\ ${ }^{e}$ Department of Surgery, Division of Cardiac Surgery, University of British Columbia, Vancouver, British Columbia, Canada \\ ${ }^{f}$ Department of Surgery, Division of Cardiac Surgery, University of Toronto, Toronto, Ontario, Canada \\ ${ }^{g}$ Department of Surgery, Division of Cardiac Surgery, University of Manitoba, Winnipeg, Manitoba, Canada \\ ${ }^{h}$ Department of Surgery, Division of Cardiothoracic Surgery, Emory University, Atlanta, Georgia, USA \\ ${ }^{i}$ Department of Family Medicine, University of Calgary, University of Calgary, Calgary, Alberta, Canada \\ ${ }^{j}$ Department of Medicine, Division of Cardiology, McMaster University, Hamilton, Ontario, Canada
}

\begin{abstract}
In 1960, Dr Nina Starr Braunwald became the first woman to perform open heart surgery. Sixty years later, despite the fact that women outnumbered men in American medical school in 2017, men still dominate the field of cardiac surgery. Women surgeons remain underrepresented in cardiac surgery; $11 \%$ of practicing cardiac surgeons in Canada were women in 2015, and $6 \%$ of practicing adult cardiac surgeons in the US were women in 2019. Although women remain a minority in other surgical specialties also, cardiothoracic surgery remains one of the most unevenly-gender distributed specialties. Why are there so few women cardiac surgeons, and why does it matter? Evidence is emerging regarding the benefits of diversity for a variety of
\end{abstract}

In 1960, Dr Nina Starr Braunwald became the first woman to perform open heart surgery. ${ }^{1}$ Sixty years later, and despite the fact that women outnumbered men in enrollment in

Received for publication June 15, 2021. Accepted July 13, 2021.

Ethics Statement: Research reported has adhered to relevant ethical guidelines.

Corresponding author: Dr Emilie P. Belley-Côté, McMaster University, David Braley Cardiac, Vascular, and Stroke Research Institute, 237 Barton Street East, Hamilton, Ontario L8L 2X2, Canada. Tel.: +1-905-527-4322, $\mathrm{x} 40741$.

E-mail: emilie.belley-cote@phri.ca

See page S93 for disclosure information.

\section{RÉSUMÉ}

En 1960, la $D^{\text {re }}$ Nina Starr Braunwald est devenue la première femme à pratiquer une chirurgie à cœur ouvert. Soixante ans plus tard, malgré le fait que les femmes étaient plus nombreuses que les hommes dans les facultés de médecine américaines en 2017 , les hommes dominent toujours le domaine de la chirurgie cardiaque. Les chirurgiennes restent sous-représentées en chirurgie cardiaque; $11 \%$ des chirurgiens praticiens en cardiologie au Canada étaient des femmes en 2015, et $6 \%$ des chirurgiens praticiens en cardiologie pour adultes aux États-Unis étaient des femmes en 2019. Bien que les femmes restent également minoritaires dans d'autres spécialités chirurgicales, la chirurgie cardiothoracique reste l'une des spécialités où la répartition

American medical schools for the first time in $2017,{ }^{2}$ men still dominate the world of cardiac surgery. Surgeons who selfidentify as women, referred to herein as women surgeons, remain underrepresented in cardiac surgery. In 2019, across all specialties in the US, women represented $36 \%$ of active physicians. ${ }^{3}$ In contrast, $11 \%$ of practicing cardiac surgeons in Canada were women in 2015, and $6 \%$ of practicing adult cardiac surgeons in the US were women in 2019. Although women are a minority in other surgical specialties, such as $20 \%$ of the current workforce in general surgery, cardiothoracic surgery remains one of the most unevenly-gender distributed specialties. ${ }^{3}$ In this review article, we discuss the 
industries, including healthcare. In order to attract and retain the best talent, we must make the cardiac surgery environment more diverse, equitable, and inclusive. Some causes of perpetuation of the gender gap have been documented in the literature - these include uneven compensation and career advancement opportunities, outdated views on family dynamics, and disproportionate scrutiny of women surgeons, causing additional workplace frictions for women. Diversity is an organizational strength, and gender-diverse institutions are more likely to outperform their non-gender-diverse counterparts. Modifiable issues perpetuate the gender gap, and mentorship is key in helping attract, develop, and retain the best and brightest within cardiac surgery. Facilitating mentorship opportunities is key to reducing barriers and bridging the gap. importance of diversity, review the documented factors contributing to the gender gap in cardiac surgery, and explore solutions to improve gender diversity specific to cardiac surgery.

\section{Why Should Diversity Be a Priority?}

Diversity, equity, and inclusion have become strategic priorities in today's leading organizations. ${ }^{5}$ Diversity is defined by the presence of differences, including differences related to gender, ethnicity, nationality, socioeconomic status, and other factors. Equity is the promotion of fairness and impartiality in access to opportunities and distribution of resources by institutions or systems. Inclusion means that institutions are truly inviting to all to participate in developmental opportunities or decision-making within the institution. ${ }^{6}$

In the past few years, many Canadian universities have made this one of their priorities. ${ }^{7}$ Similarly, it has become a focus in healthcare professions. The Consensus for the Assessment for Selection for the Health Care Professions and Specialty Training, an agreement derived from a conference held in Ottawa in 2010, states that specialist training should aim to produce a workforce that is broadly representative of the population they are taking care of. ${ }^{8}$ This consensus document also discusses ideas to broaden access to medical and health professional courses to include greater representation. ${ }^{8}$ The solutions proposed include building preparation programs to allow members of underrepresented groups to gain the skills to be competitive in entry and outreach programs. These avenues could be explored to increase gender diversity in cardiac surgery. A forecasted shortage of cardiac surgeons ${ }^{9}$ further accentuates the importance of the timely recruitment, training, and retention of all eligible and interested members of the talent pool.

In addition to social-justice considerations, evidence supports the benefits of diversity in professional environments. Diversity is beneficial to patients, ${ }^{10}$ organizations, ${ }^{11}$ and the advancement of cardiac surgery. Data from an umbrella review of 16 studies published in 2019 suggest that diversity improves performance and outcomes in medicine and surgery, des sexes est la plus inégale. Pourquoi y a-t-il si peu de chirurgiennes en cardiologie, et pourquoi est-ce important? Des données émergent au sujet des avantages de la diversité pour une variété de secteurs, y compris les soins de santé. Afin d'attirer et de retenir les meilleurs talents, nous devons rendre le milieu de la chirurgie cardiaque plus diversifié, équitable et inclusif. Certaines causes expliquant la persistance de l'écart entre les sexes ont été documentées dans la littérature : il s'agit notamment de l'inégalité de la rémunération et des possibilités d'avancement, de points de vue dépassés sur la dynamique familiale et de l'attention disproportionnée portée aux chirurgiennes, ce qui entraîne des frictions supplémentaires pour les femmes en milieu de travail. La diversité est une force au sein d'une organisation, et les établissements où la diversité des genres est présente sont plus susceptibles d'obtenir de bons résultats que les autres. Des problèmes modifiables perpétuent l'écart entre les sexes, et le mentorat est essentiel pour attirer, perfectionner et retenir les meilleurs éléments dans le domaine de la chirurgie cardiaque. II est essentiel de faciliter les possibilités de mentorat pour réduire les obstacles et combler le fossé.

with better financial performance and a higher quality of patient care. ${ }^{10}$ Financial outcomes include higher profits, innovation, and increased productivity. ${ }^{10}$ In terms of patient care, diversity has been positively correlated with improved accuracy in risk assessment and improved patient health outcomes. ${ }^{10}$

Beyond the benefits of diversity, women surgeons have been shown to have equal or better outcomes compared to those of their male counterparts. ${ }^{12}$ A population-based, retrospective, matched cohort study of 104,630 patients treated by 3314 surgeons ( $23.3 \%$ women) published in the British Medical Journal in 2017 demonstrated that having a women surgeon was independently associated with a composite endpoint of reduced mortality, reduced readmission, and reduced incidence of complications at 30 days: $11.1 \%$ (95\% confidence interval [CI] $10.9 \%$ to $11.4 \%$ ) for women vs $11.6 \%$ (95\% CI $11.3 \%$ to $11.8 \%$ ) for men; adjusted odds ratio 0.96 (95\% CI 0.92 to $0.99 ; P=0.02)$ for an aggregated group of surgeries that included cardiac surgery. ${ }^{12}$ Patients were matched for age, sex, comorbidity, rurality, income, surgeon age, years in practice, annual volume of the index procedure, specialty, and hospital type. The authors of that study commented that the observed effect might underestimate the true magnitude of the difference, as "the buffering effect of surgical teams should result in a bias towards the null, putting forth the hypothesis of an even larger discrepancy in outcomes favoring women surgeons."12

\section{What Are Some Causes of Gender Disparity in Cardiac Surgery?}

What occurs between the evenly gender-distributed medical school class ${ }^{2}$ and the skewed practicing cardiac surgeon population? Different challenges at each step of the training process, from specialty selection in medical school, to residency training and independent practice, perpetuate the gender gap in cardiac surgery.

A recent Canadian survey of 153 medical students (58.8\% women) reported similar interest toward a career in cardiac surgery from both genders: $19 \%$ of men and $17 \%$ of women 
reported high interest in applying to a cardiac surgery residency program. ${ }^{13}$ However, the main concerns or perceived barriers differed; whereas men worried more about maintaining a work-life balance during residency $(50 \%$ vs $6 \%$ for women), women feared not getting a residency position in ( $73 \%$ vs $25 \%$ for men). ${ }^{13}$ In addition, more women than men (86\% vs $64 \%, P=0.03$ ) perceived significant levels of difficulty in obtaining a residency position in the speciality. ${ }^{13}$ In light of these results, the authors hypothesized that fear of not being an appropriate match for the specialty limited women from applying to cardiac surgery programs, thus lowering the overall number of Canadian women applying to the specialty. $^{13}$

In the US, cardiothoracic surgery training can be pursued as a specialization after general surgery training. Despite increasing numbers of women in general surgery residency, the gender disparity persists in cardiac surgery. A survey by the Association of American Medical Colleges (AAMCs) circulated in 2008, with a response from a third of general surgery residents at the time, found few women committing to the specialty at graduation $(3 \%$ vs $7 \%, P<0.01)$ despite a large proportion of women initially expressing interest in cardiothoracic surgery fellowships in earlier years of training (14\% of women having interest, comparable to the $18 \%$ of male general surgery residents). ${ }^{14}$ An interesting finding in this survey is the dominant role of mentorship in specialty selection: $83 \%$ of residents cited it as the pivotal factor in their choice. ${ }^{14}$ The association between mentorship and the pursuit of a cardiac surgery career has been well documented in the 2018 Appraisal of Mentorship in Cardiothoracic Surgery Training, with $80 \%$ of surveyed thoracic surgery residents reporting mentorship as having had a high impact on their specialty selection. ${ }^{15}$ Women more often than men valued mentors as those who could serve as role models and assist with networking. ${ }^{15}$ Data show that female medical students, compared to their male counterparts, placed greater value on having a mentor of the same gender. ${ }^{16}$ Cardiac surgery may therefore be caught in a vicious circle in which the lack of female mentorship for trainees perpetuates its gender gap.

Another factor contributing to the gender gap is attrition. Although most of the data related to attrition relate to surgical training in general, cardiac surgery as a subspecialty likely follows similar patterns. During surgical training, women leave residency in higher proportions than do men. ${ }^{17} \mathrm{~A}$ number of factors, such as insufficient role models and mentors, ${ }^{15}$ gender-based discrimination, ${ }^{18,19}$ and prejudice related to childrearing and childbirth, ${ }^{20}$ have been found to explain this higher attrition rate. In a qualitative study published in The Lancet in 2019, the authors, who interviewed 12 women who had chosen to leave surgical training, offer the analogy of the collapse of a tower of blocks, with the fall of each block representing a contributor to the decision to leave surgical training, and the collapse of the tower being the decision to leave. ${ }^{17}$ Although women and men are subject to many similar factors that may contribute to their leaving surgical training, such as long working hours, fatigue and sleep deprivation, lack of learning opportunities, bullying, and unpredictable lifestyle, women face additional challenges such as the impact of pregnancy and childbirth, childrearing duties, insufficient role models, sexism and discrimination, and sexual harassment and assault. ${ }^{17}$
Data also suggest that gender-specific confidence gaps play a role in cardiac surgery training. ${ }^{21}$ In a survey of 57 thoracic surgery graduates, women reported having less-adequate preparation for board examinations than men. This finding is not reflected in actual performance, with a similar pass rate for the boards for both women and men. ${ }^{21}$ Similarly, another survey demonstrated a higher proportion of female vs male general surgery residents experiencing impostor syndrome, described as "feelings of self-doubt coupled with feelings that achievements were based in luck." 22 Impostor syndrome has been associated in the medical literature with numerous mental health comorbidities such as anxiety and depression and worsened workplace performance compared to peers. ${ }^{23}$ These gender-specific differences in perception of performance may contribute to differences in attracting, training, and retaining women in cardiac surgery.

Because surgery has been traditionally dominated by men, the surgeon stereotype includes characteristics traditionally associated with men. ${ }^{24}$ The woman surgeon is expected to assume the habitus of this surgeon culture that values "male" attributes such as assertiveness, as opposed to traditionally "female" attributes such as nurturing behaviours. ${ }^{24}$ Studies have shown that negative backlash from evaluators occurs when women go against gendered expectations in the workplace. ${ }^{25}$ The classic "double bind" from studies shows that women can be perceived as being either "competent but unlikable" or "likable but incompetent." 23 Society at present is scrutinizing the idea of gendered behavioural norms. These behavioural norms may contribute to the paucity of women in cardiac surgery.

Another roadblock for women surgeons is that they suffer more repercussions from negative outcomes, compared with their male colleagues, as shown in a study of examination of medical referral patterns. ${ }^{26}$ The impacts of negative patient outcomes are 3-fold-there is a sharper drop in referrals to women surgeons after a negative outcome; increased referrals occur for men but not women after a good outcome; and referral to all women surgeons decrease after a bad outcome from one woman surgeon, a spillover effect not noted for men surgeons. ${ }^{26}$ This association between surgeon gender and the decision to refer, irrespective of performance, unjustly punishes women more than men for medical errors. ${ }^{26}$ Female trainees witnessing these patterns may be discouraged from pursuing a surgical career.

Later in their career, for both academic and leadership pursuits, women surgeons in a survey of 100 Canadian cardiothoracic surgeons perceived that discrimination created an "unfair and unrelated to academic rank" promotional process. ${ }^{18}$ These women "believed that discrimination hindered their career development." ${ }^{18}$ In 2020, the Society of Thoracic Surgeons published the most recent data related to the cardiothoracic surgery workforce, showing that although there was an increase in women membership between 2015 and 2018 (from $8.1 \%$ to $10.3 \%$ ), it was not accompanied by a proportional rise within the Society of Thoracic Surgeons in either leadership positions on committees (from one woman in 2015 to two in 2018) or academic authorship (10.7\% to $10.4 \%$ ), further highlighting the persistent gender gap in cardiac surgery and emphasizing the importance of diversity initiatives. $^{2}$

In addition, there is evidence for disparities in pro-rated hourly earnings in Canadian surgeons, in a cross-sectional 
population-based study in $2019 .^{28}$ The difference in hourly earnings was most pronounced in cardiothoracic surgery, with a nearly $\$ 60$-per-hour difference in pay in a fee-for-service system, despite equal average operating time for women vs men surgeons. This finding points out that women cardiothoracic surgeons may be losing opportunities to perform more lucrative surgeries to their male colleagues, and hints at potential further disparities in referral patterns. ${ }^{28}$

Many factors contribute to gender disparity in cardiac surgery. These factors vary at different training and career stages. Fewer women than men enroll initially in the specialty, ${ }^{13,14}$ and in addition, women leave surgical training in higher proportions than do men. ${ }^{17}$ Gender-specific discrepancies in self-perception of performance also appear to hinder women in cardiac surgery. When in practice, women surgeons encounter unique biases related to referrals, ${ }^{26}$ and they seem to be getting fewer academic and leadership opportunities. ${ }^{18,27}$ Targeted interventions at each step of the pipeline may help improve and level the field to attract and encourage women to pursue cardiac surgery.

\section{Enabling Women's Success in Cardiac Surgery}

Initiatives could promote a more diverse, inclusive, and equitable workforce-some targeted toward women, with others aimed at increased diversity, inclusivity, and equity in general. The interventions aimed at women include mentorship opportunities, opportunities for allyship with men, and increasing the visibility of the current women cardiac surgeons. Mentorship has been cited often as a modifiable factor influencing the decision to pursue surgery, ${ }^{29}$ which holds true for cardiac surgery. ${ }^{15}$ Over $91 \%$ of 288 cardiac surgery residents surveyed viewed mentorship as "critical to success." 15 Mentorship is also beneficial beyond the training years. In a program run by the University of California, Davis School of Medicine, tangible increases in women occupying senior leadership roles resulted from targeted networking, mentorship, and career development opportunities for women. ${ }^{30}$ In addition, mentorship has been hypothesized to have been critical in attracting a higher proportion of women into transplant cardiology, compared with the field of cardiology as a whole. ${ }^{31}$

Given the scarcity of women cardiac surgeons, students have undoubtedly had difficulty finding female role models. In turn, given their scarcity, these female role models may become overburdened with mentoring responsibilities. Thus, more mentorship opportunities for both women and men surgeons are key. Given that men are the current majority of those in cardiac surgery, they should be aware of the critical role they play in standing up for inclusion, as data show that observers are more likely to be persuaded when a man confronts bias or sexism. ${ }^{32}$ The \#HeforShe movement, a solidarity movement to advocate for gender diversity, started by the United Nations, has permeated the field of cardiac surgery as well, with surgeons acknowledging the important role men have to play in advancing gender equality in cardiac surgery, including as agents of cultural change. ${ }^{33}$ Men can be great allies in the pursuit of gender equality in cardiac surgery.

Media, and nowadays social media, can go a long way in changing public perception and expanding the reach of the minority of women in cardiac surgery. ${ }^{34}$ Increasing the visibility of women in a field is known to encourage greater

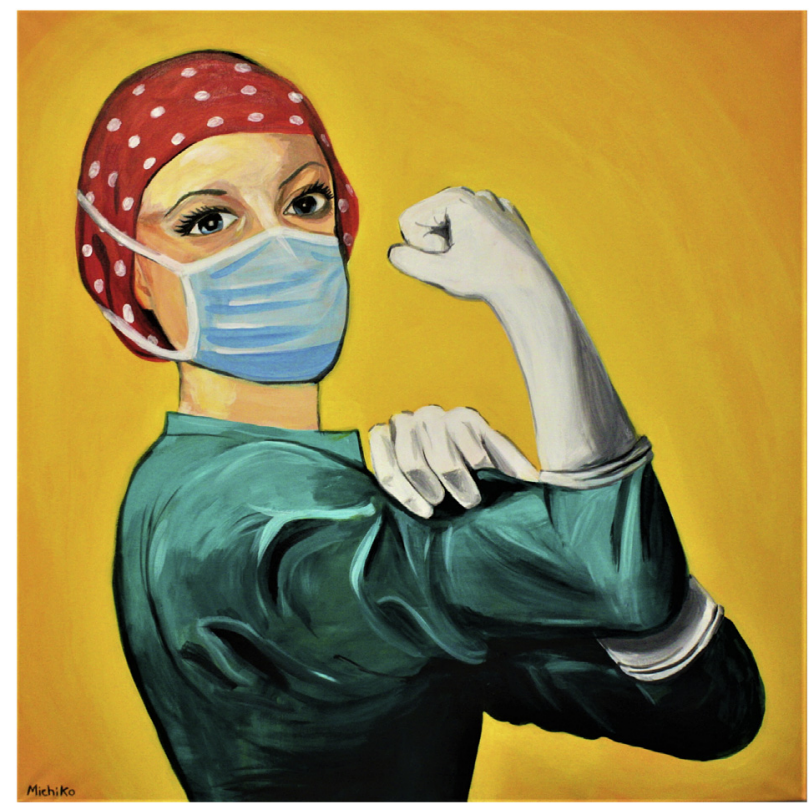

Figure 1. "Susie the Surgeon" by Dr Michiko Maruyama. "In Support of Women in Medicine, this acrylic painting is based on the 'We Can Do It!' (Rosie the Riveter) poster. After a long call shift, I picked up a paintbrush and started to paint. I was artistically and emotionally moved by a conversation I had with a medical student. She was interested in surgery, but along the way, she was told that she lacked the 'surgeon's personality,' she was 'too nice' and simply 'a woman.' Sadly, I have heard this before. To all the young girls and women who dream of becoming a surgeon and to my fellow female surgical resident colleagues, 'We Can Do It!' Thank you to all my mentors who have paved the path in fields less taken." - Dr Michiko Maruyama

representation overall (Fig. 1). ${ }^{34}$ Visibility includes social media presence, as well as representation in leadership positions and speaking engagements at conferences. Launches of social media campaigns, such as \#ILookLikeASurgeon and \#NYerORCoverChallenge, have been important in giving visibility to a diversity of role models that may not fit our preconceived notions regarding cardiothoracic surgeons. Social media thus can play an important role in affecting role modelling and changing the perception of surgeons among the public, patients, and trainees. In addition, social media may be a valuable tool to increase networking, thereby enabling mentorship opportunities for aspiring cardiac surgeons that might not have been possible before.

Broader institutional changes that are not focused on gender can improve cardiac surgery training and practice environments for women and men alike. ${ }^{17}$ Ten recommendations to aid the career advancement of women in cardiology were published in 2019, most of them targeting the workplace environment as a whole. ${ }^{36}$ These recommendations apply to cardiac surgery as well, and they include development of programs supporting work-life integration, creation of a supportive culture, and a zero tolerance for harassment. These institution-wide measures address root causes of issues that have been identified as factors that contribute to people leaving surgical training, and they improve working conditions for everyone.

In addition, promoting diversity in cardiac surgery through institutional changes has been a recent focus of healthcare 
systems worldwide, with an increasing number of recent publications pertaining to this topic. ${ }^{3,38}$ Some of those changes include celebrating women with special grants and awards, such as the Canadian Cardiovascular Society Women in Cardiovascular Medicine/Science Mentorship Award, the Women in Surgery Award by the Royal College of Surgeons of England, ${ }^{38}$ the Lady Estelle Wolfson Emerging Leaders Fellowship, the Women in Thoracic Surgery Scholarship Program, the European Society of Thoracic Surgeons (ESTS), the Women in Thoracic Surgery Scientific Session, and the Braunwald Career Development Award by the Thoracic Surgery Foundation. ${ }^{39}$ In addition, policy changes in recruitment processes in residency and beyond, and measures targeted toward surgeons with children-including lighter night-call burden for pregnant surgeons and surgeon trainees, and childcare in some centres ${ }^{37,38}$ - have paved the way to better workplaces for all. Awareness of the unique challenges women face in cardiac surgery is key to creating a more diverse, inclusive, and equitable environment.

\section{Looking Ahead}

Diversity is an organizational strength, and gender-diverse institutions are more likely to have better performance. ${ }^{40} \mathrm{Car}$ diac surgery can benefit from a more diverse, equitable, and inclusive workforce. A number of issues perpetuate the gender gap, and mentorship is key in helping to attract, develop, and retain the best and brightest within cardiac surgery. Trailblazers such as Dr Nina Starr Braunwald did not do it alone; her career was enabled by the mentorship of many prominent men surgeons at that time. ${ }^{41}$ Facilitating mentorship opportunities is key to reducing barriers and bridging the gap.

Despite the gender gap in the pool of currently practicing surgeons, the statistics on surgeons-in-training are more encouraging; $20 \%$ of newly certified cardiac surgery fellows in Canada $^{42}$ and $20 \%$ of cardiothoracic surgery residents in the US are women. ${ }^{43}$ With most women new entrants entering the workforce in the past 15 years, "one of the most striking features of the current women cardiac surgeons is its youth." 4 Studies have shown that for a minority group to be heard within a committee, a presence of at least $25 \%-30 \%$ is required to achieve a "tipping point." 19 Thus, as a discipline, we should strive to have at least that proportion of female cardiac surgeons. Moreover, our goal should be to have that proportion of women in leadership positions, including program directors, division chiefs, department chairs, and deans. ${ }^{19,45}$

Along with the huge discrepancy between the proportion of women and men in cardiac surgery, there is also the issue of other minority representation within the field. To foster a workforce representative of the population served, per the Ottawa 2010 consensus, diversity requirements extend beyond gender. ${ }^{8}$ According to a 2014 meta-analysis of 25 studies, a more diverse healthcare workforce helps reduce or eliminate racial health disparities. ${ }^{46}$ Equitable access to leadership and academic positions will be the goal for all, to ensure that the specialty continues to thrive and advance. As the Society of Thoracic Surgery puts it, "we as members of this group must invite, encourage, and guide qualified individuals from all races, cultures, genders, sexual orientation, and experiences to join us."

\section{Author's Note}

Some of the data from the US are for cardiothoracic surgery more broadly, as opposed to cardiac surgery specifically. Cardiac surgeons in the US are also trained in thoracic surgery, whereas in Canada the 2 specialties have distinct training pathways. In this article, we have aggregated the cardiothoracic surgery evidence with that relating to cardiac surgery when no breakdown of data was available for cardiac vs thoracic surgery.

\section{Funding Sources}

The authors have no funding sources to declare.

\section{Disclosures}

The authors have no conflicts of interest to disclose.

\section{Acknowledgements}

The authors acknowledge all the mentors and allies in our lives, women and men alike, who have paved the way for us thus far.

\section{References}

1. Waldhausen JA. In memoriam: Nina S. Braunwald, 1928-1992. Ann Thorac Surg 1993;55:1055-6.

2. Association of American Medical Colleges (AAMC). More women than men enrolled in U.S. medical schools in 2017. Available at: https://www. aamc.org/news-insights/press-releases/more-women-men-enrolled-usmedical-schools-2017. Accessed March 6, 2021.

3. Association of American Medical Colleges (AAMC). Active physicians by sex and specialty. Available at: https://www.aamc.org/data-reports/workforce/ interactive-data/active-physicians-sex-and-specialty-2019. Accessed March 14, 2021.

4. Ikonomidis JS, Boden N, Atluri P. The Society of Thoracic Surgeons Thoracic Surgery Practice and Access Task Force-2019 workforce report. Ann Thorac Surg 2020;110:1082-90.

5. Backhus LM, Kpodonu J, Romano JC, et al. An exploration of myths, barriers, and strategies for improving diversity among STS members. Ann Thorac Surg 2019;108:1617-24.

6. eXtension Foundation Impact Collaborative. Diversity, equity, and inclusion. Available at: https://dei.extension.org/. Accessed June 12, 2021.

7. University Affairs. Most universities report having equity, diversity and inclusion plans, but challenges remain. Available at: https://www. universityaffairs.ca/news/news-article/most-universities-report-havingequity-diversity-and-inclusion-plans-but-challenges-remain/. Accessed June 122021.

8. Prideaux D, Roberts C, Eva K, et al. Assessment for selection for the health care professions and specialty training: consensus statement and recommendations from the Ottawa 2010 Conference. Med Teach 2011;33:215-23.

9. Moffatt-Bruce S, Crestanello J, Way DP, Williams TE. Providing cardiothoracic services in 2035: signs of trouble ahead. J Thorac Cardiovasc Surg 2018;155:824-9.

10. Gomez LE, Bernet P. Diversity improves performance and outcomes. J Natl Med Assoc 2019;111:383-92. 
11. Shaikh U, Acosta DA, Freischlag JA, Young HM, Villablanca AC. Developing diverse leaders at academic health centers: a prerequisite to quality health care? Am J Med Qual 2018;33:440-2.

12. Wallis CJ, Ravi B, Coburn N, et al. Comparison of postoperative outcomes among patients treated by male and female surgeons: a population based matched cohort study. BMJ 2017;359:j4366.

13. Hage A, Hage D, Guo L. Concerns and perceived obstacles for females with regards to cardiac surgery residency - a survey. J Card Surg 2020;35: 2539-42.

14. Vaporciyan AA, Reed CE, Erikson C, et al. Factors affecting interest in cardiothoracic surgery: survey of North American general surgery residents. J Thorac Cardiovasc Surg 2009;137:1054-62.

15. Stephens EH, Goldstone AB, Fiedler AG, et al. Appraisal of mentorship in cardiothoracic surgery training. J Thorac Cardiovasc Surg 2018;156: 2216-23.

16. Faucett EA, McCrary HC, Milinic T, et al. The role of same-sex mentorship and organizational support in encouraging women to pursue surgery. Am J Surg 2017;214:640-4.

17. Liang R, Dornan T, Nestel D. Why do women leave surgical training? A qualitative and feminist study. Lancet 2019;393:541-9.

18. Dresler CM, Padgett DL, MacKinnon SE, Patterson GA. Experiences of women in cardiothoracic surgery. A gender comparison. Arch Surg 1996;131:1128-34. discussion 1135 .

19. Ceppa DP, Dolejs SC, Boden N, et al. Gender bias and its negative impact on cardiothoracic surgery. Ann Thorac Surg 2020;109:14-7.

20. Pham DT, Stephens EH, Antonoff MB, et al. Birth trends and factors affecting childbearing among thoracic surgeons. Ann Thorac Surg 2014;98:890-5.

21. Luc JGY, Moon MR, Antonoff MB. Impact of sex on confidence and perception of training in cardiothoracic surgery. Am Surg 2020;86: e119-21.

22. Leach PK, Nygaard RM, Chipman JG, Brunsvold ME, Marek AP. Impostor phenomenon and burnout in general surgeons and general surgery residents. J Surg Educ 2019;76:99-106.

23. Bravata DM, Watts SA, Keefer AL, et al. Prevalence, predictors, and treatment of impostor syndrome: a systematic review. J Gen Intern Med 2020;35:1252-75.

24. issuu/BIBA Publishing. Vascular Specialist. Available at: https://issuu. com/bibapublishing/docs/2019_04vas_apr19_lowres_digital. Accessed March 7, 2021.

25. Tinsley CH, Cheldelin SI, Schneider AK, Amanatullah ET. Women at the bargaining table: pitfalls and prospects. Negotiation J 2009;25: $233-48$.

26. Sarsons H. Interpreting signals in the labor market: evidence from medical referrals [job market paper]. Available at: https://scholar.harvard. edu/sarsons/publications/interpreting-signals-evidence-medical-referrals. Accessed March 7, 2021.

27. Olive JK, Preventza OA, Blackmon SH, Antonoff MB. Representation of women in the Society of Thoracic Surgeons authorship and leadership positions. Ann Thorac Surg 2020;109:1598-604.

28. Dossa F, Simpson AN, Sutradhar R, et al. Sex-based disparities in the hourly earnings of surgeons in the fee-for-service system in Ontario, Canada. JAMA Surg 2019;154:1134.
29. Marks IH, Diaz A, Keem M, et al. Barriers to women entering surgical careers: a global study into medical student perceptions. World J Surg 2020;44:37-44.

30. Bauman MD, Howell LP, Villablanca AC. The Women in Medicine and Health Science program: an innovative initiative to support female faculty at the University of CaliforniaDavis School of Medicine. Acad Med 2014;89:1462-6.

31. Hunt SA. Women leaders in cardiac transplantation. Circulation 2019;139:1005-6.

32. Johnson WB, Smith DG. How men can confront other men about sexist behavior. Available at: https://hbr.org/2020/10/how-men-can-confrontother-men-about-sexist-behavior. Accessed March 7, 2021.

33. Wood DE. How can men be good allies for women in surgery? \#HeForShe. J Thorac Dis 2021;13:492-501.

34. Antonoff MB, Stamp N. The \#NYerORCoverChallenge: what it means for women in cardiothoracic surgery. J Thorac Cardiovasc Surg 2017;154:1349-51.

35. Luc JGY, Stamp NL, Antonoff MB. Social media as a means of networking and mentorship: role for women in cardiothoracic surgery. Available at: https://www.semthorcardiovascsurg.com/article/S10430679(18)30165-5/abstract. Accessed March 7, 2021.

36. Sharma G, Sarma AA, Walsh MN, et al. 10 recommendations to enhance recruitment, retention, and career advancement of women cardiologists. J Am Coll Cardiol 2019;74:1839-42.

37. Kobayashi AK. Women in thoracic surgery: Asian perspective. J Thorac Dis 2021;13:456-9.

38. Pompili C, Veronesi G, Novoa NM, et al. Women in thoracic surgery: European perspectives. J Thorac Dis 2021;13:439-47.

39. Kane L, Litle VR, Blackmon SH, Yanagawa J. The national and global impact of "Women in Thoracic Surgery." J Thorac Dis 2021;13:432-8.

40. Shannon G, Jansen M, Williams K, et al. Gender equality in science, medicine, and global health: Where are we at and why does it matter?. Available at: https://www.thelancet.com/journals/lancet/article/ PIIS0140-6736(18)33135-0/fulltext. Accessed March 7, 2021.

41. Sabharwal N, Dev H, Smail H, Mcgiffin D, Saxena P. Nina Braunwald: a female pioneer in cardiac surgery. Texas Heart Inst J 2017;44:96-100.

42. Randhawa VK, Banks L, Rayner-Hartley E, et al. Canadian women in cardiovascular medicine and science: moving toward parity. Can J Cardiol 2017;33:1339-41.

43. Stephens EH, Robich MP, Walters DM, et al. Gender and cardiothoracic surgery training: specialty interests, satisfaction, and career pathways. Ann Thorac Surg 2016;102:200-6.

44. Donington JS, Litle VR, Sesti J, Colson YL. The WTS report on the current status of women in cardiothoracic surgery. Ann Thorac Surg 2012;94:452-9.

45. Weiss A, Lee KC, Tapia V, et al. Equity in surgical leadership for women: more work to do. Am J Surg 2014;208:494-8.

46. LaVeist TA, Pierre G. Integrating the 3Ds-social determinants, health disparities, and health-care workforce diversity. Public Health Rep 2014;129(suppl 2):9-14. 